Wright State University

CORE Scholar

$12-4-2000$

\title{
Ga-Doped ZnO Films Grown on GaN Templates by Plasma- Assisted Molecular-Beam Epitaxy
}

H. J. Ko

Yanfang Chen

Wright State University - Main Campus, yanfang.chen@wright.edu

S. K. Hong

H. Wenisch

T. Yao

See next page for additional authors

Follow this and additional works at: https://corescholar.libraries.wright.edu/physics

Part of the Physics Commons

\section{Repository Citation}

Ko, H. J., Chen, Y., Hong, S. K., Wenisch, H., Yao, T., \& Look, D. C. (2000). Ga-Doped ZnO Films Grown on GaN Templates by Plasma-Assisted Molecular-Beam Epitaxy. Applied Physics Letters, 77 (23),

3761-3763.

https://corescholar.libraries.wright.edu/physics/67

This Article is brought to you for free and open access by the Physics at CORE Scholar. It has been accepted for inclusion in Physics Faculty Publications by an authorized administrator of CORE Scholar. For more information, please contact library-corescholar@wright.edu. 
Authors

H. J. Ko, Yanfang Chen, S. K. Hong, H. Wenisch, T. Yao, and David C. Look

This article is available at CORE Scholar: https://corescholar.libraries.wright.edu/physics/67 


\title{
Ga-doped ZnO films grown on GaN templates by plasma-assisted molecular-beam epitaxy
}

\author{
H. J. Ko, ${ }^{\text {a) }}$ Y. F. Chen, S. K. Hong, H. Wenisch, and T. Yao \\ Institute for Materials Research, Tohoku University, Katahira, Aoba-Ku, Sendai 980-8577, Japan \\ D. C. Look \\ Semiconductor Research Center, Wright State University, Dayton, Ohio 45435
}

(Received 8 August 2000; accepted for publication 9 October 2000)

\begin{abstract}
We have investigated the structural and optical properties of Ga-doped $\mathrm{ZnO}$ films grown on $\mathrm{GaN}$ templates by plasma-assisted molecular-beam epitaxy. The carrier concentration in Ga-doped $\mathrm{ZnO}$ films can be controlled from $1.33 \times 10^{18} / \mathrm{cm}^{3}$ to $1.13 \times 10^{20} / \mathrm{cm}^{3}$. Despite high Ga incorporation, the linewidth of (0002) $\omega$-rocking curves of Ga-doped $\mathrm{ZnO}$ films still lies in the range from 5 to 15 arc min. Photoluminescence (PL) spectra of Ga-doped $\mathrm{ZnO}$ films show dominant near-bandedge emission with negligibly weak deep-level emission, independent of carrier concentration. The PL spectrum exhibits a new emission line at $3.358 \mathrm{eV}$, which corresponds to exciton emission bound to a Ga donor. To avoid degradation of the PL intensity, the maximum dopability of $\mathrm{Ga}$ in $\mathrm{ZnO}$ is determined to be around $2.6 \times 10^{19} / \mathrm{cm}^{3}$. (C) 2000 American Institute of Physics.
\end{abstract}

[S0003-6951(00)02050-7]

$\mathrm{ZnO}$ is a II-VI compound semiconductor with a direct band gap of $3.37 \mathrm{eV}$ at room temperature. Recently, it has attracted considerable attention because of its large exciton binding energy of $60 \mathrm{meV}$. This large exciton binding energy enables optically pumped excitonic lasing at room temperature, ${ }^{1,2}$ and high-temperature stimulated emission up to $550 \mathrm{~K}$ due to exciton mechanism. ${ }^{3}$ So far, high-quality $\mathrm{ZnO}$ layers have been grown either pulsed laser deposition ${ }^{4}$ or plasma-assisted molecular-beam epitaxy (P-MBE)., $\mathrm{ZnO}$ layers can be grown in a layer-by-layer mode, ${ }^{5,6}$ which have lead to the growth of $\mathrm{ZnO}$ layers with high quality enough to show biexciton emission. ${ }^{7}$ The next major focus will be on conductivity control by impurity doping.

Undoped $\mathrm{ZnO}$ films generally exhibit $n$-type conduction with typical carrier concentration of $\sim 10^{17} / \mathrm{cm}^{3} .{ }^{8,9}$ It should be mentioned that the control of carrier concentration in $n$-type $\mathrm{ZnO}$ has not been achieved yet for single-crystalline epilayers, although carrier concentration in a range from $10^{18}$ to $10^{20} / \mathrm{cm}^{3}$ will be needed for laser-diode application. This letter will report on the control of carrier concentration of $n$-type $\mathrm{ZnO}$ films up to $\sim 10^{20} / \mathrm{cm}^{3}$ by doping with $\mathrm{Ga}$.

Group III elements $\mathrm{Al}, \mathrm{Ga}$, In, and group VII elements $\mathrm{Cl}$ and I can be used as $n$-type dopants in $\mathrm{P}-\mathrm{MBE}$ of $\mathrm{ZnO}$ films. Because of high reactivity of $\mathrm{Al}$, oxidation of the $\mathrm{Al}$ source during $\mathrm{ZnO}$ growth may become a problem. $\mathrm{Ga}$ and In are less reactive and more resistive to oxidation, compared to $\mathrm{Al}$. $\mathrm{Cl}$ and I may have a memory effect, so that the residual electron concentration would not be low after $\mathrm{Cl}$ or I were used. On the other hand, the covalent bond lengths of $\mathrm{Ga}-\mathrm{O}$ and $\mathrm{Zn}-\mathrm{O}$ are estimated to be 1.92 and $1.97 \AA$, respectively using atomic radii, ${ }^{10}$ which should be compared with those of $\mathrm{In}-\mathrm{O}(2.1 \AA)$ and $\mathrm{Zn}-\mathrm{Cl}(2.3 \AA)$. A slightly smaller bond length of $\mathrm{Ga}-\mathrm{O}$ than that of $\mathrm{Zn}-\mathrm{O}$ is expected

\footnotetext{
a) Author to whom correspondence should be addressed; electronic mail: koko@imr.tohoku.ac.jp
}

to make the deformation of the $\mathrm{ZnO}$ lattice small even in the case of high Ga concentration, while the larger bond lengths of $\mathrm{In}-\mathrm{O}$ and $\mathrm{Zn}-\mathrm{Cl}$ would deform the $\mathrm{ZnO}$ lattice more seriously. This is why Ga has been selected as a $n$-type dopant in $\mathrm{ZnO}$ in our experiments.

Ga-doped $\mathrm{ZnO}$ films have been grown on $4-\mu$ m-thick epitaxial GaN layers by $\mathrm{P}-\mathrm{MBE}$. The epitaxial $\mathrm{GaN}$ was $n$ type with a carrier concentration of $6 \times 10^{16} / \mathrm{cm}^{3}$. The growth of Ga-doped $\mathrm{ZnO}$ films was carried out at $750{ }^{\circ} \mathrm{C}$ with a $\mathrm{Zn}$ equivalent flux of $1.5 \AA / \mathrm{s}$ and an oxygen flow rate of $1.5 \mathrm{sccm}$, which gave rise to an oxygen rich condition. The thickness of the Ga-doped $\mathrm{ZnO}$ films was around 0.65 $\mu \mathrm{m}$.

Figure 1 shows room temperature carrier concentrations (dots) of Ga-doped $\mathrm{ZnO}$ films measured by the van der Pauw method as a function of Ga cell temperature, and the calcu-

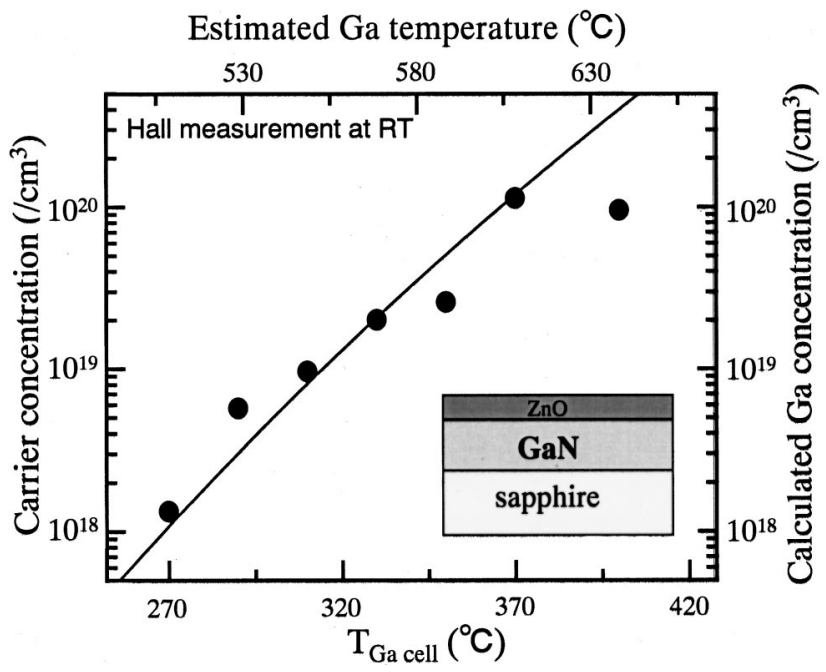

FIG. 1. Carrier concentration (dots) of $n$-type $\mathrm{ZnO}$ films doped with $\mathrm{Ga}$ as a function of $\mathrm{Ga}$ cell temperature and calculated $\mathrm{Ga}$ concentration (solid line) vs estimated $\mathrm{Ga}$ temperature. 


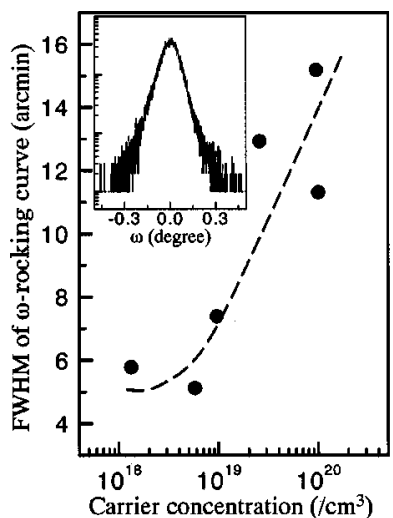

(a)

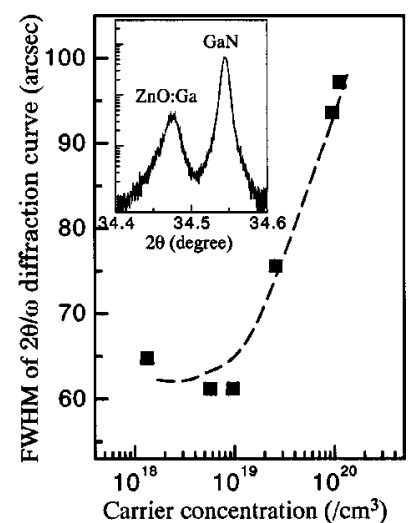

(b)
FIG. 2. FWHM values of (a) $\omega$-rocking curve and (b) $2 \theta / \omega$ diffraction curve of the (0002) reflection of Ga-doped $\mathrm{ZnO}$ films as a function of carrier concentration. Insets show (a) $\omega$-rocking curve and (b) $2 \theta / \omega$ diffraction curve of the (0002) reflection of a Ga-doped $\mathrm{ZnO}$ film with a carrier concentration of $9.6 \times 10^{18} / \mathrm{cm}^{3}$.

lated $\mathrm{Ga}$ concentration (solid curve) versus estimated $\mathrm{Ga}$ source temperature. The $\mathrm{Ga}$ concentration $\left(N_{\mathrm{Ga}}\right)$ incorporated in the films was calculated by $N_{\mathrm{Ga}}=p\left[N_{A} /\right.$ $\left.\left(2 \pi m_{\mathrm{Ga}} k_{B} T_{\mathrm{Ga}}\right)\right]^{1 / 2} / v_{G}$, where $p$ is the vapor pressure of $\mathrm{Ga}$, $N_{A}$ and $k_{B}$ are the Avogadro and Boltzmann constants, respectively, $m_{\mathrm{Ga}}$ and $T_{\mathrm{Ga}}$ are the $\mathrm{Ga}$ atom weight and the estimated $\mathrm{Ga}$ source temperature, respectively, and $v_{G}$ is the growth rate. As the $\mathrm{Ga}$ cell temperature increases from 270 to $400{ }^{\circ} \mathrm{C}$, the electron concentration increases exponentially from $1.33 \times 10^{18} / \mathrm{cm}^{3}$ to $1.13 \times 10^{20} / \mathrm{cm}^{3}$, and the electron mobility $(\mu)$ decreases $\left(\mu=120.5 \mathrm{~cm}^{2} \mathrm{~V}^{-1} \mathrm{~s}^{-1}\right.$ for 1.33 $\times 10^{18} / \mathrm{cm}^{3}, \mu=36.7 \mathrm{~cm}^{2} \mathrm{~V}^{-1} \mathrm{~s}^{-1}$ for $2.58 \times 10^{19} / \mathrm{cm}^{3}$, and $\mu=51.1 \mathrm{~cm}^{2} \mathrm{~V}^{-1} \mathrm{~s}^{-1}$ for $\left.9.53 \times 10^{19} / \mathrm{cm}^{3}\right)$. The increment of carrier concentration up to around $10^{20} / \mathrm{cm}^{3}$ is in good agreement with the variation of calculated $\mathrm{Ga}$ concentration, which suggests that most of the incorporated Ga atoms form shallow donors and are activated at room temperature. As the Ga cell temperature exceeds $400{ }^{\circ} \mathrm{C}$, the carrier concentration shows a tendency toward saturation due to an onset of carrier compensation.

Figure 2 shows full width at half maximum (FWHM) values of (a) $\omega$-rocking curves and (b) $2 \theta / \omega$ diffraction curves of the (0002) reflection of Ga-doped $\mathrm{ZnO}$ films as a function of carrier concentration. The insets in Fig. 2 show typical diffraction curves of the (0002) reflection of a $\mathrm{ZnO}$ film with a carrier concentration of $9.6 \times 10^{18} / \mathrm{cm}^{3}$ for both $\omega$ and $2 \theta / \omega$ scans. The line profiles for both diffraction curves are well fitted by Gaussian curves, which implies that Ga doping causes neither degradation of interface nor serious change in crystal structure, even at high doping level up to $\sim 10^{20} / \mathrm{cm}^{3}$. As the carrier concentration in Ga-doped $\mathrm{ZnO}$ layers increases from $1.33 \times 10^{18} / \mathrm{cm}^{3}$ to $1.13 \times 10^{20} / \mathrm{cm}^{3}$, both FWHM values for $\omega$ and $2 \theta / \omega$ diffraction curves gradually increase from 5 to 15 arc min and 61 to 94 arc sec, respectively. Such a gradual increase in the linewidth of diffraction curves is generally observed in impurity doped crystals and can be attributed to increase in local strain around impurity atoms or point defects associated with the impurity atoms. $^{11,12}$ We note, however, such a gradual increase in FWHM value would be overtaken by an abrupt increase when a considerable change in lattice structure occurred,

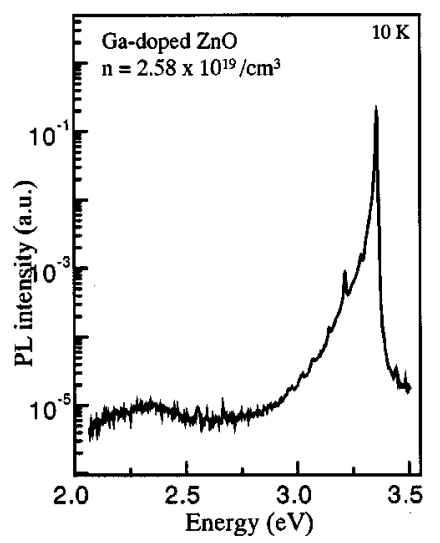

(a)

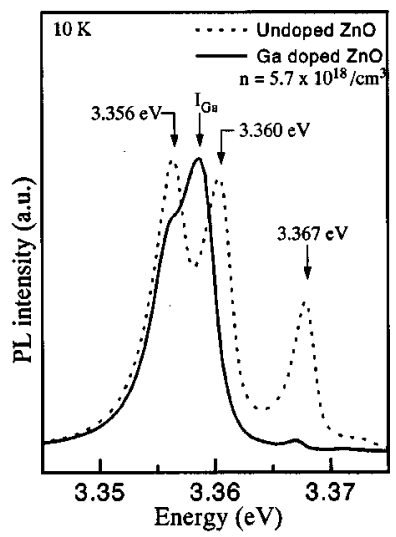

(b)
FIG. 3. (a) PL spectrum for Ga-doped $\mathrm{ZnO}$ film with a carrier concentration of $5.7 \times 10^{18} / \mathrm{cm}^{3}$, and (b) bound exciton emission spectra of undoped $\mathrm{ZnO}$ (dotted curve) and Ga-doped $\mathrm{ZnO}$ (solid curve) films.

such as formation of small angle grain boundaries, generation of dislocations, and stacking faults. It should also be noted that the FWHM values of the (0002) $\omega$-rocking curves of $\mathrm{Ga}$-doped $\mathrm{ZnO}$ layers lie in the range of undoped $\mathrm{ZnO}$ layers. ${ }^{13} \mathrm{We}$ stress that despite high $\mathrm{Ga}$ doping, $\mathrm{ZnO}$ films exhibit only slight degradation in crystal structure.

Figure 3(a) shows a low temperature photoluminescence (PL) spectrum of a Ga-doped $\mathrm{ZnO}$ layer with a carrier concentration of $2.58 \times 10^{19} / \mathrm{cm}^{3}$. The excitation intensity of the $325 \mathrm{~nm}$ line from a $\mathrm{He}-\mathrm{Cd}$ laser was $80 \mathrm{~mW} / \mathrm{cm}^{2}$. The bound excitonic emission dominates the PL spectrum [Fig. 3(a)], while deep-level emission at around $2.3 \mathrm{eV}$ is negligibly weak. The deep-level emission intensity shows only slight variation with carrier concentration as shown in Fig. 4, although the x-ray diffraction linewidth increases with carrier concentration (Fig. 2). These facts imply that Ga doping does not contribute to the creation of defects responsible for the deep-level emission, but it produces local strain around $\mathrm{Ga}$ atoms or point defects associated with Ga impurities which do not affect the deep-level emission.

Figure 3(b) shows details of the bound exciton emission

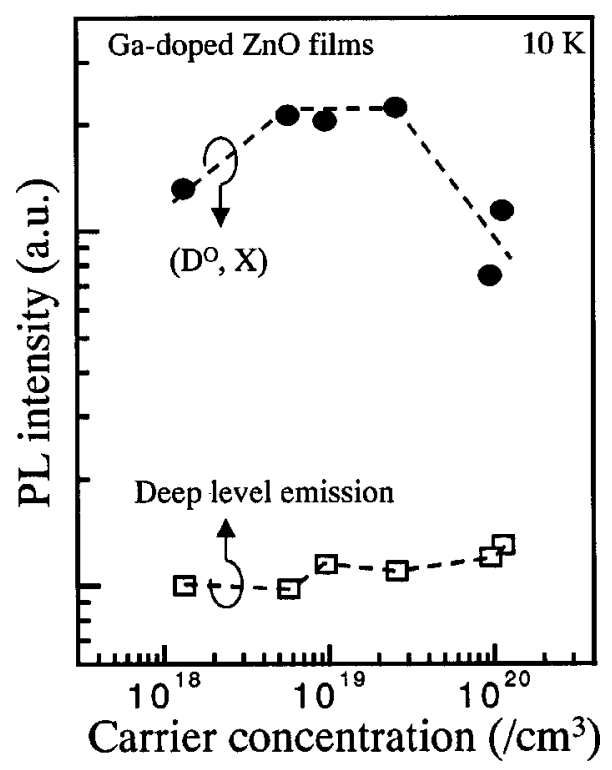

FIG. 4. Integrated PL intensity of $I_{\mathrm{Ga}}$ emission for Ga-doped $\mathrm{ZnO}$ films as a function of carrier concentration. 
spectra of undoped $\mathrm{ZnO}$ (dotted curve) and Ga-doped $\mathrm{ZnO}$ (solid curve) films with a carrier concentration of 5.7 $\times 10^{18} / \mathrm{cm}^{3}$. The bound exciton emission lines at 3.356 , 3.360, and $3.367 \mathrm{eV}$ dominate the PL spectrum of undoped $\mathrm{ZnO}$ films. These emission lines could be correlated with defect complexes, as was conjectured in an earlier work. ${ }^{14}$ In that case, after a high-temperature anneal, only the lowestenergy $(3.356 \mathrm{eV})$ exciton survived. It is noted that Ga doping makes a considerable change in the bound exciton emission spectrum. The PL spectrum of Ga-doped $\mathrm{ZnO}$ shows a new emission line at $3.358 \mathrm{eV}$ which hereafter is called $I_{\mathrm{Ga}}$. The emission line at $3.360 \mathrm{eV}$ disappears, while emission lines at 3.356 and $3.367 \mathrm{eV}$ are greatly reduced in intensity. We suggest that the newly observed emission line $I_{\mathrm{Ga}}$ can be ascribed to bound exciton emission associated with a $\mathrm{Ga}$ donor.

The integrated PL intensity of $I_{\mathrm{Ga}}$ emission is plotted in Fig. 4 as a function of carrier concentration at room temperature. The PL intensity increases with increasing carrier concentration up to $5.7 \times 10^{18} / \mathrm{cm}^{3}$. Then, it shows a saturation behavior until $2.58 \times 10^{19} / \mathrm{cm}^{3}$, beyond which it decreases abruptly. The same such behavior is generally observed in impurity-doped semiconductors and is understood in the following manner: The increase of the PL intensity in the low carrier concentration regime is due to an increase in the intensity of the impurity-related emission, which is the Gadonor related exciton emission $I_{\mathrm{Ga}}$ in the present case. However, the doping of impurities higher than a certain threshold would generate defects. Those defects would reduce the emission intensity by introducing either radiative deep levels or nonradiative channels. At high doping levels impurity clusters or impurity-defect complexes may limit radiative efficiency. ${ }^{15}$ A similar phenomenon was observed by Tsang et al. ${ }^{16}$ in GaP crystals. They interpreted the behavior of their bound exciton emission as being due to nonradiative Auger recombination processes associated with delocalized electrons in the impurity band. It is suggested from Fig. 4 that those two competing factors balance in the carrier concentration range of $10^{19} / \mathrm{cm}^{3}$ and the formation of defects or nonradiative channels dominates for carrier concentration higher than $3 \times 10^{19} / \mathrm{cm}^{3}$, presumably due to the onset of carrier compensation as is observed in Fig. 1. We conclude that the dopability of $\mathrm{Ga}$ in $\mathrm{ZnO}$ is limited to $2.6 \times 10^{19} / \mathrm{cm}^{3}$, at least in terms of PL.

In conclusion, we have demonstrated that the carrier concentration in $n$-type $\mathrm{ZnO}$ films grown by $\mathrm{P}-\mathrm{MBE}$ on $\mathrm{GaN}$ templates can be well controlled from $1.33 \times 10^{18} / \mathrm{cm}^{3}$ to $1.13 \times 10^{20} / \mathrm{cm}^{3}$. The effective doping of $\mathrm{Ga}$, with minimized carrier compensation, is achieved even for the high carrier concentration of $1.13 \times 10^{20} / \mathrm{cm}^{3}$. The FWHM value of the (0002) x-ray rocking curves of the Ga-doped $\mathrm{ZnO}$ films increases from 5 to 15 arc min with increasing carrier concentration, which is still within the FWHM values of undoped $\mathrm{ZnO}$ films. Low-temperature PL spectra of Ga-doped $\mathrm{ZnO}$ show dominant bound exciton emission at $3.358 \mathrm{eV}$ and negligibly weak deep-level emission at around $2.3 \mathrm{eV}$. This bound exciton emission emerges by Ga doping and overtakes the bound exciton emissions observed in undoped $\mathrm{ZnO}$ layers. The intensity of $I_{\mathrm{Ga}}$ emission increases with carrier concentration up to $5.7 \times 10^{18} / \mathrm{cm}^{3}$, shows a saturation behavior from $5.7 \times 10^{18} / \mathrm{cm}^{3}$ to $2.58 \times 10^{19} / \mathrm{cm}^{3}$, and eventually rapidly decreases above $2.58 \times 10^{19} / \mathrm{cm}^{3}$. The maximum dopability of $\mathrm{Ga}$ in $\mathrm{ZnO}$ is inferred to be around 2.6 $\times 10^{19} / \mathrm{cm}^{3}$, if PL quality is used as a criterion.

${ }^{1}$ D. M. Bagnall, Y. F. Chen, Z. Zhu, T. Yao, S. Koyama, M. Y. Shen, and T. Goto, Appl. Phys. Lett. 70, 2230 (1997).

${ }^{2}$ Z. K. Tang, G. K. L. Wong, P. Yu, M. Kawasaki, A. Ohtomo, H. Koinuma, and Y. Segawa, Appl. Phys. Lett. 72, 3270 (1998).

${ }^{3}$ D. M. Bagnall, Y. F. Chen, Z. Zhu, T. Yao, M. Y. Shen, and T. Goto, Appl. Phys. Lett. 73, 1038 (1998).

${ }^{4}$ R. D. Vispute, V. Talyansky, S. Choopun, R. P. Sharma, T. Venkatesan, M. He, X. Tang, J. B. Halpern, M. G. Spencer, Y. X. Li, L. G. SalamancaRiba, A. A. Iliadis, and K. A. Jones, Appl. Phys. Lett. 73, 348 (1998).

${ }^{5}$ H. J. Ko, Y. F. Chen, S. K. Hong, and T. Yao, J. Cryst. Growth 209, 816 (2000).

${ }^{6}$ Y. F. Chen, H. J. Ko, S. K. Hong, and T. Yao, Appl. Phys. Lett. 76, 559 (2000).

${ }^{7}$ H. J. Ko, Y. F. Chen, and T. Yao, Appl. Phys. Lett. 77, 537 (2000).

${ }^{8}$ S. Bethke, H. Pan, and B. W. Wessels, Appl. Phys. Lett. 52, 138 (1988).

${ }^{9}$ S. Choopun, R. D. Vispute, W. Noch, A. Balsamo, R. P. Sharma, T. Venkatesan, A. Iliadis, and D. C. Look, Appl. Phys. Lett. 75, 3947 (1999).

${ }^{10} \mathrm{C}$. Kittel, Introduction to Solid State Physics, 6th ed. (Wiley, New York, 1986), p. 76.

${ }^{11}$ T. Nina, T. Minato, and K. Yoneda, Jpn. J. Appl. Phys., Part 2 21, L387 (1982).

${ }^{12}$ K. Ohkawa, T. Mitsuyu, and O. Yamazaki, J. Appl. Phys. 62, 3216 (1987).

${ }^{13}$ H. J. Ko, Y. F. Chen, S. K. Hong, H. Wenisch, and T. Yao (private communication).

${ }^{14}$ D. C. Reynolds, D. C. Look, B. Jogai, C. W. Litton, T. C. Collins, W. Harsch, and G. Cantwell, Phys. Rev. B 57, 12151 (1998).

${ }^{15}$ V. Swaminathan and A. T. Macrander, Materials Aspects of GaAs and InP Based Structures (Prentice-Hall, Englewood Cliffs, NJ, 1991), p. 319.

${ }^{16}$ J. C. Tsang, P. J. Dean, and P. T. Landsberg, Phys. Rev. 173, 814 (1968). 